\title{
Post Partum Hemorrhage - Mini Review
}

\section{Charalampos Voros, Kalliopi Pappa}

$1^{\text {st }}$ Department of Obstetrics and Gynecology, "Alexandra" Hospital, Medical School, National and Kapodistrian University of Athens, Athens, Greece

\section{Corresponding Author}

Charalampos Voros, e-mail: charalamposvoros@hotmail.com

\section{Abstract}

Background: Postpartum hemorrhage (PPH) remains a common cause of maternal mortality worldwide, mainly caused by uterine atony. Medical intervention plays an important part in prevention and therapies of PPH. Prophylactic interventions include the use of uterotonic drugs. We elaborated the consistency of national and international guidelines on those medical approaches. Materials and methods: Medical approaches in PPH were extracted from recent publications. Furthermore, the current guidelines of the World Health Organization, the FIGO and of the American, British,and Canadian of Obstetricians and Gynecologists on PPH were analyzed. Results: Use of oxytocin after delivery of the anterior shoulder is the most important and effective component of this practice. However, the examined guidelines fail to give unequivocal recommendations on further uterotonics in $\mathrm{PPH}$, which may partially be attributed to differing publication dates of the guidelines. Conclusion: Appropriate management of postpartum hemorrhage requires prompt diagnosis and treatment. International guidelines on PPH are characterized by differing recommendations. However, recent publications suggest that adhering to local guidelines significantly reduces the prevalence of severe $\mathrm{PPH}$.

Key words: postparrum hemorrhage, bleeding, cesarian delivery, oxytocin, placenta disorders, coagulopathy, uterine atony, uterine balloon

\section{Introduction}

Postpartum hemorrhage (PPH) is an obstetric emergency. It is one of the top causes of maternal mortality in both high and low income countries, although the absolute risk of death from PPH is much lower in high-income countries. Timely diagnosis, appropriate resources, and management are critical for preventing death.
Postpartum bleeding is often defined as the loss of more than $500 \mathrm{ml}$ or $1,000 \mathrm{ml}$ of blood within the first 24 hours following childbirth ${ }^{1,2}$.

In 2017, the American College of Obstetricians and Gynecologists revised their definition of PPH from the classic one $(\geq 500 \mathrm{~mL}$ after vaginal birth or $\geq 1000 \mathrm{~mL}$ after cesarean delivery) to (1) cumulative 
blood loss $\geq 1000 \mathrm{~mL}$ or (2) bleeding associated with signs/symptoms of hypovolemia within 24 hours of the birth process regardless of delivery route in order to reduce the number of women inappropriately labeled with this diagnosis ${ }^{3}$.

This topic will present an overview of major issues relating to $\mathrm{PPH}$. Clinical use of specific medical and minimally invasive interventions, and surgical interventions at laparotomy ${ }^{4}$.

Although vasodilatation due to neuraxial anesthesia and vasovagal reactions may result in lightheadedness/syncope, tachycardia, and hypotension, these entities are less likely postpartum than $\mathrm{PPH}$, and they are readily reversible and generally not dangerous. Lightheadedness, tachycardia, or hypotension is unlikely to be due to neuraxial anesthesia if the woman was hemodynamically stable prior to delivery, the level of the block did not become significantly higher immediately following delivery, and symptoms did not abruptly follow systemic administration of a drug known to cause hypotension ${ }^{5}$.

\section{Pathogenesis}

The most common cause of PPH is uterine atony, which complicates 1 in 40 births in the United States and is responsible for at least 75 percent of cases of PPH. Risk factors for uterine atony include prolonged labor, precipitous labor, uterine distension (multi-fetal gestation, polyhydramnios, fetal macrosomia), fibroid uterus, chorioamnionitis, indicated magnesium sulfate infusions, and prolonged use of oxytocin. Ineffective uterine contraction, either focally or diffusely, is additionally associated with a diverse range of etiologies including retained placental tissue, placental disorders (such as morbidly adherent placenta, placenta previa, and abruption placentae), coagulopathy (increased fibrin degradation products) and uterine inversion. Body mass index (BMI) above 40 (class III obesity) is also a recognized risk factor for postpartum uterine atony.
The diagnosis of atony is generally made when the uterus does not become firm after routine management of the third stage of labor. Atony may or may not be associated with retained tissue ${ }^{6}$. Placental disorders (eg, morbidly adherent placenta, placenta previa, abruptio placentae), retained products of conception, and uterine inversion result in PPH because they inhibit effective uterine contraction. With diffuse atony, blood loss can be much greater than observed because a flaccid and dilated uterus may contain a significant amount of blood. With focal localized atony, the fundal region may be well contracted while the lower uterine segment is dilated (ballooning) and atonic, which is difficult to appreciate on abdominal examination, but may be detected on vaginal examination.

Trauma-related bleeding can be due to lacerations or surgical incisions. Cervical and vaginal lacerations may develop as a result of the natural processes of delivery or may be related to provider interventions. They may not be noted until excessive postpartum vaginal bleeding prompts lower genital tract examination, including examination for vaginal and vulvar hematomas.Corpus lacerations may be complete transmyometrial ruptures or incomplete lacerations of the inner myometrium ${ }^{7}$.

At cesarean delivery, hemorrhage from the uterine incision is generally caused by lateral extension of the incision, which can result from spontaneous tearing of an edematous lower segment during an otherwise uneventful cesarean delivery after prolonged labor, from an incision made too low or not sufficiently curved on the lower segment, or from delivery of the fetus through an incision that is too small.

Coagulopathy is a cause of PPH in women with an inherited or acquired bleeding diathesis, and a result of PPH when there is a severe reduction of clotting factors due to persistent heavy bleeding and hemodilution of the remaining clotting factors. Acute coagulopathies can be caused by amniotic 
fluid embolism, placental abruption, preeclampsia with severe features, or HELLP syndrome.

\section{Risk Classification}

The California quality improvement ${ }^{8}$. toolkit classifies patients as low, medium, or high risk for $\mathrm{PPH}$ :

Low Risk: Singleton pregnancy, fewer than four previous deliveries, chorioamnionitis, obesity (BMI $>35$ ), estimated fetal weight $>4,000 \mathrm{gr}$

Medium Risk: Prior uterine surgery,more than four previous deliveries,multiplegestation,large fibroids and chorioamnionitis

High Risk: Suspected placenta accreta or percretam hematocrit $<30 \%$, platelets $<100,000$ and active bleeding on admission

\section{Management}

When hemorrhage is suspected as the cause of hemodynamic instability, initial (and expedited) management with blood and blood products is advised (as opposed to large volume crystalloid infusion). Hypovolemic hemorrhagic shock is treated withaggressive volume resuscitation with packed red cellsand other appropriate blood products. Transfusion should keep up with blood loss, with early activation of a protocol for large volume transfusion in those patients with heavy bleeding. Development of a standardized institutional approach to massive transfusion improves outcome. There are no data from clinical trials of $\mathrm{PPH}$ to help guide management of transfusion specifically in PPH

Uterine massage is a simple first line treatment as it helps the uterus to contract to reduce bleeding. Although the evidence around the effectiveness of uterine massage is inconclusive, it is common practice after the delivery of the placenta.

Intravenous oxytocin is the drug of choice for postpartum hemorrhage ${ }^{9}$. Ergotamine may also be used $^{10}$.

Oxytocin helps the uterus to contract quickly and the contractions to last for longer ${ }^{11}$. It is the first line treatment for PPH when its cause is the uterus not contracting well. A combination of syntocinon and ergometrine is commonly used as part of active management of the third stage of labor ${ }^{12}$. This is called syntometrine. It does reduce the risk of PPH by improving the tone of the uterus when compared with no treatment however it has to be used with caution due to its effect raising blood pressure and causing worse after pains.

Carbetocin compared with oxytocin produced a reduction in women who needed uterine massage and further uterotonic drugs for women having caesarean sections ${ }^{13}$. There was no difference in rates of PPH in women having caesarean sections or women having vaginal deliveries when given carbetocin ${ }^{14}$. Carbetocin appears to cause less adverse effects. More research is needed to find the cost effectiveness of using carbetocin ${ }^{15}$.

Tranexamic acid, a clot stabilizing medication, may also be used to reduce bleeding and blood transfusions in low-risk women ${ }^{16}$, however evidence as of 2015 was not strong.

\section{Classification of Hemorrhage}

Stage 0: normal - treated with fundal massage and oxytocin.

Stage 1: more than normal bleeding - establish large-bore intravenous access, assemble personnel, increase oxytocin, consider use of methergine, perform fundal massage, prepare 2 units of packed red blood cells.

Stage 2: bleeding continues - check coagulation status, assemble response team, move to operating room, place intrauterine balloon, administer additional uterotonics (misoprostol, carboprosttromethamine), consider: uterine artery embolization, dilatation and curettage, and laparotomy with uterine compression stitches or hysterectomy.

Stage 3: bleeding continues - activate massive 
transfusion protocol, mobilize additional personnel, recheck laboratory tests, perform laparotomy, consider hysterectomy ${ }^{17}$.

\section{Surgery}

Surgery may be used in case of cervical lacerations or tear or uterine rupture or medical management fails. Methods used may include uterine artery ligation, ovarian artery ligation, internal iliac artery ligation, selective arterial embolization, B-lynch suture, and hysterectomy ${ }^{18-20}$. Bleeding caused by traumatic causes should be management by surgical repair.

\section{Prevention}

Active management of the third stage is a method of shortening the stage between when the baby is born and when the placenta is delivered ${ }^{21}$. This stage is when the mother is at risk of having a PPH. Active management involves giving a drug which helps the uterus contract before delivering the placenta by a gentle but sustained pull on the umbilical cord whilst exerting upward pressure on the lower abdomen to support the uterus (controlled cord traction) ${ }^{22}$.

Another method of active management which is not recommended now is fundal pressure during the delivery of the placenta. A review into this method found no research and advises controlled cord traction because fundal pressure can cause the mother unnecessary pain ${ }^{23}$. Allowing the cord to drain appears to shorten the third stage and reduce blood loss but evidence around this subject is not strong enough to draw solid conclusions ${ }^{24}$.

Nipple stimulation and breastfeeding triggers the release of natural oxytocin in the body, therefore it is thought that encouraging the baby to suckle soon after birth may reduce the risk of PPH for the mother ${ }^{25}$. A review looking into this did not find enough good research to say whether or not nipple stimulation did reduce PPH. More research is needed to answer this question ${ }^{26}$.

\section{References}

1. Callaghan WM, Kuklina EV, Berg CJ. Trends in postpartum hemorrhage: United States, 19942006. Am J ObstetGynecol 2010; 202:353.e1.

2. Marshall AL, Durani U, Bartley A, et al. The impact of postpartum hemorrhage on hospital length of stay and inpatient mortality: a National Inpatient Sample-based analysis. Am J ObstetGynecol 2017; 217:344.e1.

3. Lockwood CJ, Schatz F. A biological model for the regulation of peri-implantational hemostasis and menstruation. J SocGynecolInvestig 1996; 3:159.

4. Lockwood CJ, Nemerson Y, Krikun G, et al. Steroidmodulated stromal cell tissue factor expression: a model for the regulation of endometrial hemostasis and menstruation. J ClinEndocrinolMetab 1993; 77:1014.

5. Lockwood CJ. Regulation of plasminogen activator inhibitor 1 expression by interaction of epidermal growth factor with progestin during decidualization of human endometrial stromal cells. Am J ObstetGynecol 2001; 184:798.

6. Lockwood CJ, Krikun G, Schatz F. The decidua regulates hemostasis in human endometrium. SeminReprodEndocrinol 1999; 17:45.

7. Bateman BT, Berman MF, Riley LE, Leffert LR. The epidemiology of postpartum hemorrhage in a large, nationwide sample of deliveries. AnesthAnalg 2010; 110:1368.

8. Conrad LB, Groome LJ, Black DR. Management of Persistent Postpartum Hemorrhage Caused by Inner Myometrial Lacerations. ObstetGynecol 2015; 126:266.

9. Sheiner E, Sarid L, Levy A, et al. Obstetric risk factors and outcome of pregnancies complicated with early postpartum hemorrhage: a population-based study. J Matern Fetal Neonatal Med 2005; 18:149.

10. Mhyre JM, Shilkrut A, Kuklina EV, et al. Massive blood transfusion during hospitalization for de- 
livery in New York State, 1998-2007. ObstetGynecol 2013; 122:1288.

11. Rouse DJ, Leindecker S, Landon M, et al. The MFMU Cesarean Registry: uterine atony after primary cesarean delivery. Am J ObstetGynecol 2005; 193:1056.

12. Cheng YW, Delaney SS, Hopkins LM, Caughey AB. The association between the length of first stage of labor, mode of delivery, and perinatal outcomes in women undergoing induction of labor. Am J ObstetGynecol 2009; 201:477.e1.

13. Blomberg M. Maternal obesity and risk of postpartum hemorrhage. ObstetGynecol 2011; 118:561.

14. Wetta LA, Szychowski JM, Seals S, et al. Risk factors for uterine atony/postpartum hemorrhage requiring treatment after vaginal delivery. Am J ObstetGynecol 2013; 209:51.e1.

15. Kramer MS, Berg C, Abenhaim H, et al. Incidence, risk factors, and temporal trends in severe postpartum hemorrhage. Am J ObstetGynecol 2013; 209:449.e1.

16. Sharp GC, Saunders PT, Greene SA, et al. Intergenerational transmission of postpartum hemorrhage risk: analysis of 2 Scottish birth cohorts. Am J ObstetGynecol 2014; 211:51.e1.

17. Bruning AH, Heller HM, Kieviet N, et al. Antidepressants during pregnancy and postpartum hemorrhage: a systematic review. Eur J ObstetGynecolReprodBiol 2015; 189:38.

18. Oberg AS, Hernandéz-Diaź $\mathrm{S}$, Frisell T, et al. Genetic contribution to postpartum haemorrhage in Swedish population: cohort study of 466,686 births. BMJ 2014; 349:g4984.

19. Giannella L, Mfuta K, Pedroni D, et al. Delays in the delivery room of a primary maternity unit: a retrospective analysis of obstetric outcomes. J Matern Fetal Neonatal Med 2013; 26:593.

20. Lim G, Melnyk V, Facco FL, et al. Cost-effectiveness Analysis of Intraoperative Cell Salvage for Obstetric Hemorrhage. Anesthesiology 2018; 128:328.

21. Salati JA, Leathersich SJ, Williams MJ, et al. Prophylactic oxytocin for the third stage of labour to prevent postpartum haemorrhage. Cochrane Database Syst Rev 2019; 4:CD001808.

22. Lakshmi SD, Abraham R. Role of Prophylactic Tranexamic Acid in Reducing Blood Loss during Elective Caesarean Section: A Randomized Controlled Study. J ClinDiagn Res 2016; 10:QC17.

23. Dilla AJ, Waters JH, Yazer MH. Clinical validation of risk stratification criteria for peripartum hemorrhage. ObstetGynecol 2013; 122:120.

24. Novello A, King JC. Health advisory: Prevention of maternal deaths through improved management of hemorrhage. www.acog.org/acog_districts/dist_notice.cfm?recno=1\&bulletin $=1517$ (Accessed on May 02, 2006).

Received 26-7-2019

Revised 2-9-2019

Accepted 9-9-2019 